\title{
Detecção e variabilidade de Plasmopara halstedii no Brasil e avaliação da resistência de genótipos de girassol ao míldio
}

\author{
Regina Maria Villas Bôas de Campos Leite ${ }^{1}$, Ademir Assis Henning ${ }^{1}$, Silvia Rosa Rodrigues ${ }^{2}$, Marcelo Fernandes de \\ Oliveira $^{1}$
}

\author{
${ }^{1}$ Embrapa Soja, CP 231, 86001-970, Londrina, PR, e-mail: regina@cnpso.embrapa.br \\ ${ }^{2}$ Estagiária da Embrapa Soja, Universidade Estadual de Londrina, Londrina, PR. \\ Autora para correspondência: Regina M.V.B.C. Leite \\ Data da chegada: 24/03/2006. Aceito para publicação em: 30/4/2007.
}

\section{RESUMO}

Leite, R.M.V.B.C.; Henning, A.A.; Rodrigues, S.R.; Oliveira, M.F. Detecção e variabilidade de Plasmopara halstedii no Brasil e avaliação da resistência de genótipos de girassol ao míldio. Summa Phytopathologica, v.33, n.4, p.335-340, 2007.

Este trabalho foi conduzido com o objetivo de identificar a raça fisiológica de Plasmopara halstedii que ocorreu em plantas de girassol coletadas no campo experimental da Embrapa Soja, Londrina, PR, em 1998, 2001 e 2002 e avaliar a reação de genótipos de girassol ao míldio. Plântulas de girassol das diferenciadoras de raças e das cultivares foram inoculadas com suspensão de zoosporângios do patógeno e foram plantadas em caixas contendo areia autoclavada. As plântulas foram mantidas em câmara climatizada, com temperatura controlada em $21^{\circ} \mathrm{C}$, por 11 dias. Em seguida, as plantas foram aspergidas intensamente com água destilada, cobertas com saco plástico e mantidas no escuro, a $18^{\circ} \mathrm{C}$. No dia seguinte, foi observada a presença de esporulação nos cotilédones.
As plantas que apresentaram esporulação foram consideradas suscetíveis e as sem esporulação foram resistentes. O resultado indicou tratar-se da raça 330 (antiga raça 7 americana), nas três ocasiões. Os genótipos de girassol Embrapa 122, BRS 191 e as cultivares de girassol ornamental BRS Capri M, BRS Encanto M, BRS Oásis, BRS Paixão M, BRS Pesqueiro M, BRS Refúgio M, BRS Saudade M e BRS Saudade U e seus respectivos parentais foram suscetíveis a $P$. halstedii raça 330. Os genótipos AGROBEL 910, AGROBEL 920, AGROBEL 960, AGROBEL 965, C11, EXP38, M734, M742 e RUMBOSOL 91 foram resistentes à raça 330 do patógeno e podem ser indicados aos agricultores para uso em regiões de risco de ocorrência da doença.

Palavras-chave adicionais: Helianthus annuus, raça fisiológica, resistência genética

\section{ABSTRACT}

Leite, R.M.V.B.C.; Henning, A.A.; Rodrigues, S.R.; Oliveira, M.F. Detection and variability of Plasmopara halstedii in Brazil and resistance of sunflower genotypes to downy mildew. Summa Phytopathologica, v.33, n.4, p.335-340, 2007.

This research was carried out for identifying the physiological race of Plasmopara halstedii occurring in sunflower at the experimental field of Embrapa Soybean, Londrina, PR, Brazil, in 1998, 2001 and 2002 by evaluating the reaction of sunflower genotypes inoculated with downy mildew pathogen. Sunflower seedlings of the differentials set to identify races and of the cultivars were inoculated by immersion in zoosporangia suspension and were grown in autoclaved sand boxes. Seedlings were kept in growing chambers at $21^{\circ} \mathrm{C}$ for 11 days. After this period, plants were intensively misted with distilled water, covered with plastic bag, and kept in the dark at $18^{\circ} \mathrm{C}$. In the next day, sporulation in cotyledons was observed. Plants with sporulation were considered susceptible and non-sporulated plants were resistant. Results indicated the occurrence of race 330 (former American race 7) in the three years evaluated. Sunflower genotypes Embrapa 122, BRS 191 and ornamental sunflower cultivars BRS Capri M, BRS Encanto M, BRS Oásis, BRS Paixão M, BRS Pesqueiro M, BRS Refúgio M, BRS Saudade M and BRS Saudade U and respective parents were susceptible to $P$. halstedii race 330 . The genotypes AGROBEL 910, AGROBEL 920, AGROBEL 960, AGROBEL 965, C11, EXP38, M734, M742 and RUMBOSOL 91 were resistant to that race and can be used by the growers in regions of high potential for disease occurrence.

Additional Keywords: Helianthus annuus, physiological race, genetic resistance

O míldio, causado pelo oomiceto Plasmopara halstedii (Farlow) Berlese \& de Toni, é uma das principais doenças do girassol no mundo, por ser potencialmente muito destrutivo. Sua distribuição mundial torna-a uma das doenças mais temidas pelos órgãos encarregados da sanidade dos cultivos de girassol. A maioria dos países tem regulamentações específicas para evitar a introdução ou a dispersão do patógeno (16), inclusive o Brasil, onde é considerado objeto de quarentena categoria " $\mathrm{A}$ ".
O míldio é originário da América do Norte e espalhou-se dos Estados Unidos para várias localidades do mundo, através de sementes infectadas por $P$. halstedii. Com a movimentação do girassol cultivado ao redor do mundo, é atualmente endêmico em todos os locais onde o girassol é cultivado, porém o patógeno é mais prevalecente e os danos mais severos em regiões temperadas, quando comparadas com as regiões subtropicais. Os danos atribuídos ao míldio variam de acordo com a porcentagem de plantas infectadas, a distribuição e as condições 
climáticas durante a estação de crescimento, que afetam o desenvolvimento da doença. A doença afeta a produção pela morte das plantas, pela diminuição no tamanho de capítulos e pelo menor teor de óleo e peso dos aquênios (6).

Os sintomas da doença se manifestam em todas as fases do crescimento vegetativo, ainda que os danos sejam mais graves quanto mais cedo se apresente o ataque. O míldio pode apresentar diferentes tipos de sintomas, dependendo da idade da planta, da reação do genótipo e das condições de umidade e temperatura. $\mathrm{O}$ tombamento resulta da infecção do sistema radicular das plantas, nos estádios iniciais de desenvolvimento, sob condições de temperatura amena e alta umidade. Esse sintoma manifesta-se devido à presença de inóculo primário no solo (oósporos), podendo afetar as plântulas antes ou logo após a emergência, com redução do estande. As plantas com infecção sistêmica apresentam crescimento lento ou nanismo, com folhas cloróticas e anormalmente grossas, hastes quebradiças com capítulos eretos e geralmente estéreis. O sintoma inicial é o amarelecimento do primeiro par de folhas verdadeiras, quase sempre na base das folhas ou ao longo da nervura central. Com o crescimento da planta, o patógeno alastra-se, aumentando as áreas cloróticas, inclusive nas folhas que nascem sucessivamente. Por ocasião do florescimento, plantas infectadas sistemicamente apresentam altura de $0,1 \mathrm{~m}$ a $1,0 \mathrm{~m}$, enquanto que plantas sadias possuem $1,5 \mathrm{~m}$ a $1,8 \mathrm{~m}$. Em condições favoráveis, há a formação de estruturas brancoacinzentadas, compostas de esporangióforos e zoosporângios, na face inferior das folhas cloróticas. A infecção localizada pode ser observada nas folhas jovens, inicialmente como manchas angulares, pequenas, verde-amareladas, distribuídas ao acaso no limbo foliar. Essas manchas podem aumentar de tamanho, coalescer e tomar grande parte da folha. Estruturas do oomiceto podem ser vistas na face inferior da folha correspondente às lesões, persistindo, por algum tempo, em condições de alta umidade relativa, e desaparecendo rapidamente, em condições de seca. Quando afeta o sistema radicular, o patógeno causa a galha basal, caracterizada pela redução do número de raízes secundárias, que se apresentam descoloridas, rugosas e hipertrofiadas, aumentando a sensibilidade da planta à seca $(6,9,18)$.

No Brasil, o míldio foi encontrado pela primeira vez em 1982, nas localidades de Santo Augusto e Veranópolis, no Rio Grande do Sul e, posteriormente, em 1983, em Londrina, PR (4). Todavia, a ocorrência do patógeno foi em parcelas experimentais, sendo as plantas infectadas imediatamente arrancadas e queimadas. Estudos sobre a identificação da raça ocorrente foram realizados por Henning \& França Neto (8), determinando a presença da raça 2 americana (raça 300, na atual nomenclatura). Posteriormente, em 1993, na localidade de Curitiba, PR, suspeitou-se da ocorrência da doença em parcelas experimentais, todavia não foi identificada a raça (12).

Em julho de 1998, plantas de girassol da variedade Embrapa 122 com sintomas de míldio foram detectadas no campo experimental da Embrapa Soja, em Londrina, PR. Os mesmos sintomas foram novamente observados no local em agosto de 2001, maio e setembro de 2002, em plantas da cultivar BRS 191 e de girassol ornamental. Medidas de erradicação das plantas foram tomadas no campo experimental da Embrapa Soja. As plantas com alguma sintomatologia foram arrancadas e queimadas, de modo a evitar a disseminação do patógeno. Exemplares foram conservados em laboratório para identificação do agente causal e da raça.

Este trabalho teve como objetivo identificar a raça fisiológica de $P$. halstedii que ocorreu no Brasil e avaliar a reação de genótipos de girassol, visando caracterizar fontes de resistência para serem utilizadas na criação de cultivares resistentes ao míldio, no programa de melhoramento genético de girassol da Embrapa Soja. Resultados parciais foram previamente comunicados em reuniões de pesquisa $(10,11,13)$.

\section{MATERIAL E MÉTODOS}

Plantas de girassol com sintomas de míldio foram coletadas no campo experimental da Embrapa Soja, em julho de 1998, agosto de 2001 e setembro de 2002. Os trabalhos de preparo de inóculo e inoculação foram realizados no Laboratório de Fitopatologia. Os testes de avaliação foram realizados em câmaras climatizadas, com luminosidade e temperatura controladas.

\section{Preparo do inóculo, inoculação e avaliação}

As plantas com sintomas de míldio foram coletadas no campo e mantidas em sacos plásticos em ultrafreezer, a $-80^{\circ} \mathrm{C}$. No laboratório, o patógeno foi visualizado ao microscópio, observando-se micélio e zoosporângios semelhantes aos de $P$. halstedii, agente causal do míldio do girassol. Para confirmação da patogenicidade e identificação da raça, foi utilizada a metodologia descrita por Gulya (5).

Sementes de girassol das diferenciadoras de raça e das cultivares foram embebidas em solução de hipoclorito de sódio a 1,5\% (Q-boa a $20 \%$ ) por 10 minutos. Em seguida, as sementes foram lavadas em água corrente, até a remoção do produto. Cinqüenta sementes de cada material foram colocadas para germinar em caixa gerbox, sobre papel umedecido, à temperatura ambiente $\left(25^{\circ} \mathrm{C}\right)$, por três dias. Sementes com algum tipo de contaminação por fungos ou bactérias foram descartadas. A suspensão de zoosporângios do oomiceto foi preparada a partir de folhas com esporulação abundante retiradas do ultrafreezer. Os zoosporângios foram lavados com água destilada. A concentração de esporos foi ajustada para 20.000 zoosporângios $/ \mathrm{mL}$ com auxílio de hemacitômetro, tendo sido adicionado $1 \mathrm{~mL}$ da solução de cálcio $(2,2 \mathrm{~g}$ de $\mathrm{CaCl}_{2}$ anidro em $10 \mathrm{~mL}$ de água destilada). Plântulas com cerca de $1,5 \mathrm{~cm}$ a $2 \mathrm{~cm}$ de radícula foram imersas na suspensão de zoosporângios de $P$. halstedii e incubadas por quatro horas, a $15^{\circ} \mathrm{C}$, no escuro. Em seguida, foram plantadas em caixas contendo areia autoclavada. As plântulas foram irrigadas diariamente e mantidas na câmara climatizada, com temperatura controlada em $21^{\circ} \mathrm{C}$, até as primeiras folhas verdadeiras terem $1 \mathrm{~cm}$ (aproximadamente 11 dias). Após esse período, ao final da tarde, as plantas foram aspergidas intensamente com água destilada e cobertas com saco plástico, de modo a fazer uma câmara úmida, e mantidas no escuro, a $18^{\circ} \mathrm{C}$. No dia seguinte, foi observada a presença de esporulação abundante nos cotilédones das plantas. Na avaliação, as plantas que apresentaram esporulação nos cotilédones foram consideradas suscetíveis e as sem esporulação foram resistentes. Após a leitura, o material foi descartado e incinerado em local apropriado.

\section{Identificação da raça fisiológica}

Os testes para a identificação da raça de $P$. halstedii foram realizados quatro vezes: em agosto de 1998, com material recém-coletado do campo; em outubro de 2001, com plantas doentes recém-coletadas das parcelas experimentais da Embrapa Soja; em janeiro de 2002, com o inóculo coletado em outubro de 2001 que ficou armazenado em ultrafreezer; e em setembro de 2002, com material recém-coletado do campo e com o inóculo de outubro de 2001 armazenado em ultrafreezer. Para identificação da raça fisiológica, foram empregadas as nove linhagens diferenciadoras, conforme Gulya et al. (7). As linhagens CMSHA30379NW22 (USDA) e 89V23960 (Embrapa Soja) também foram testadas, além da variedade Embrapa 122, incluída como 
Tabela 1. Reação de diferenciadoras de raças de Plasmopara halstedii observada após a inoculação com o patógeno, em Londrina, PR, em 1998, 2001 e 2002 .

\begin{tabular}{|c|c|c|c|c|c|c|}
\hline \multirow{2}{*}{ Designação } & \multirow[t]{2}{*}{ Diferenciadora original * } & \multirow[t]{2}{*}{ Diferenciadora utilizada * } & \multicolumn{4}{|c|}{ Reação observada** } \\
\hline & & & Ago 1998 & Out 2001 & Jan 2002 & Set2002 \\
\hline D-1 & HA 304 & HA 304 , IS003 & $\mathrm{S}$ & $\mathrm{S}$ & $\mathrm{S}$ & S \\
\hline D-3 & RHA 274 & RHA 274 & $\mathrm{R}$ & $\mathrm{R}$ & $\mathrm{R}$ & $\mathrm{R}$ \\
\hline D-4 & PMI3 & DM-2 & $\mathrm{S}$ & $\mathrm{S}$ & $\mathrm{S}$ & $\mathrm{S}$ \\
\hline D-5 & PM-17 & PM-17 & NT & S & $\mathrm{S}$ & $\mathrm{S}$ \\
\hline D- 8 & QHP1 & HAR-5 & $\mathrm{R}$ & $\mathrm{R}$ & $\mathrm{R}$ & $\mathrm{R}$ \\
\hline D-9 & HA 335 & HA 335 & $\mathrm{R}$ & $\mathrm{R}$ & $\mathrm{R}$ & $\mathrm{R}$ \\
\hline Testemunha & & Embrapa 122 & $\mathrm{~S}$ & NT & $\mathrm{NT}$ & $\mathrm{S}$ \\
\hline Testemunha & & $89 V 23960$ & NT & $\mathrm{S}$ & $\mathrm{S}$ & $\mathrm{S}$ \\
\hline Testemunha & & CMSHA30379NW22 & NT & S & S & $\mathrm{S}$ \\
\hline Adicional & & RHA 325 & NT & $\mathrm{R}$ & $\mathrm{R}$ & $\mathrm{R}$ \\
\hline
\end{tabular}

* De acordo com Gulya et al. (7)

** S - suscetível; R - resistente; NT - não testado

testemunha suscetível. Também foi incluída a linhagem RHA 325, objetivando diferenciar as raças americanas 6 ou 7 (nomenclatura antiga).

\section{Reação de genótipos de girassol a $P$. halstedii}

Com os objetivos de avaliar a reação de genótipos de girassol e pesquisar fontes de resistência para serem utilizadas na criação de cultivares resistentes ao míldio, três experimentos de inoculação de sementes de variedades, híbridos e linhagens com a raça 330 de $P$. halstedii foram realizados, em condições de câmara climatizada, com luminosidade e temperatura controladas.

No primeiro experimento, realizado em novembro de 2001, foram avaliados os genótipos comerciais AGROBEL 910, AGROBEL 920, AGROBEL 960, BRS 191, C11, Embrapa 122, M734, M742, RUMBOSOL 91 e as linhagens CMSHA30379NW22 e 89V23960, incluídas como testemunhas suscetíveis.

No segundo experimento, realizado em abril de 2003 e repetido em outubro de 2003, foram avaliados 27 híbridos e 24 linhagens CMS ou HA de girassol. A variedade Embrapa 122 foi incluída como testemunha suscetível. Os métodos de inoculação e de avaliação foram os mesmos empregados nos testes de identificação de raça.

O terceiro experimento foi conduzido com oito cultivares de girassol ornamental (14) e respectivos parentais (Tabela 1), totalizando 24 genótipos, além da linhagem 89V23960 (Embrapa Soja), incluída como testemunha suscetível e do híbrido Agrobel 960, utilizado com testemunha resistente. $\mathrm{O}$ teste de reação de genótipos ornamentais foi realizado duas vezes, em abril e outubro de 2003.

\section{RESULTADOS E DISCUSSÃO}

A avaliação das plantas diferenciadoras inoculadas com suspensão de zoosporângios de $P$. halstedii demonstrou que os genótipos HA 335, RHA 274, HAR-4, 803-1, HAR-5 e a diferenciadora adicional RHA 325 não apresentaram esporulação, sendo caracterizados como resistentes. Os genótipos Embrapa 122, CMSHA30379NW22, 89V23960, HA 304, IS003, PM-17, RHA 265 e DM-2 foram categorizados como suscetíveis, pois exibiram esporulação abundante na região dos cotilédones. O mesmo resultado foi observado nos quatro testes de identificação da raça (Tabela 1).

A nomenclatura utilizada para descrever as raças de $P$. halstedii era muito ambígua, já que as raças eram chamadas tanto pelo nome da região de origem (raça Red River, raça européia), por números (raças 1 a 9 da nomenclatura americana) ou letras (raças A a D da nomenclatura francesa). Para uniformizar a nomenclatura, fitopatologistas de girassol reuniram-se em janeiro de 1998 em Fargo, Dakota do Norte, Estados Unidos (7), e propuseram um sistema de nove diferenciadoras (linhagens de girassol de domínio público denominadas de D1 a D9) reagrupadas em trincas. Para codificar a raça, uma nota é atribuída para cada trinca, baseada na reação de suscetibilidade ou resistência dos genótipos. A nota corresponde à soma dos coeficientes atribuídos aos genótipos da trinca, que mostraram reação de suscetibilidade: 1 para o primeiro, 2 para o segundo e 4 para o terceiro. No caso de resistência do genótipo, é atribuída nota zero. A nomenclatura completa da raça corresponde à justaposição das notas obtidas com as três trincas (18).

A primeira trinca consiste de três linhagens de USDA. HA 304, proposta como suscetível universal, é suscetível a todas as raças. Das outras duas linhagens, também do USDA, RHA 265 é resistente à raça 1 e RHA 274 tem resistência às raças 1 e 2 (7).

A segunda trinca de diferenciadoras consiste de PMI3, PM-17 e 803-1. PMI3 é uma seleção do INRA a partir do composto do USDA DM-2. PM-17 é uma linhagem selecionada de PI 406022 por Rama Urs of Dahlgren. A linhagem 803-1 foi selecionada pelo programa de melhoramento do Institute of Field \& Vegetable Crops, Novi Sad, Sérvia e Montenegro e possui resistência às raças 1, 2, 3 e 4 de míldio, mas é suscetível à raça 5 (7).

A terceira trinca das diferenciadoras consiste de HAR-4, QHP1 e HA 335. HAR foi selecionada por possuir resistência a quatro raças do agente causal da ferrugem (Puccinia helianthi) da América do Norte, mas HAR-4 e HAR-5 também possuem resistência a todas as raças conhecidas de $P$. halstedii. QHP1 foi selecionada a partir de um cruzamento incluindo HAR-5 (INRA). Finalmente, a linhagem HA 335 foi proposta como o genótipo resistente a todas as raças de $P$. halstedii conhecidas (7).

Seguindo a ordem pré-estabelecida das diferenciadoras, de acordo com as reações de suscetibilidade e resistência observadas, o resultado obtido nos testes de identificação de raça indicou que o patógeno que ocorreu em Londrina pertence à raça 330 (na nomenclatura nova) ou raça 7 americana (na antiga). Essa confirmação se deu com a avaliação da linhagem RHA 325, que mostra reação de suscetibilidade à raça $6 \mathrm{e}$ resistência à raça 7 (17). Cabe salientar que a raça 7 foi a prevalecente na Argentina, na década de 1990 (1). Posteriormente, na safra 2000- 
Tabela 2. Reação de genótipos de girassol inoculados com Plasmopara halstedii raça 330, em Londrina, PR, em novembro de 2001.

\begin{tabular}{lll}
\hline Genótipo & Identificação & Reação observada \\
\hline AGROBEL 910 & Híbrido & Resistente \\
AGROBEL 920 & Híbrido & Resistente \\
AGROBEL 960 & Híbrido & Resistente \\
BRS 191 & Híbrido & Suscetível \\
C11 & Híbrido & Resistente \\
Embrapa 122 & Variedade & Suscetível \\
M734 & Híbrido & Resistente \\
M742 & Híbrido & Resistente \\
RUMBOSOL 91 & Híbrido & Resistente \\
CMSHA30379NW22 & Testemunha & Suscetível \\
89V23960 & Testemunha & Suscetível \\
\hline
\end{tabular}

Tabela 3. Reação de genótipos de girassol inoculados com Plasmopara halstedii raça 330, em Londrina, PR, em abril e outubro de 2003.

\begin{tabular}{|c|c|c|c|c|}
\hline Genótipo & Identificação & $\begin{array}{c}\text { Reação } \\
\text { *abril } \\
2003\end{array}$ & $\begin{array}{c}\text { Reação } \\
\text { *outubro } \\
2003\end{array}$ & $\begin{array}{c}\text { Reação } \\
\text { observada } \\
*\end{array}$ \\
\hline $1 / 2$ & Híbrido & $\mathrm{S}$ & $\mathrm{S}$ & $\mathrm{S}$ \\
\hline $13 / 14$ & Híbrido & $\mathrm{S}$ & $\mathrm{S}$ & $\mathrm{S}$ \\
\hline $19 / 20$ & Híbrido & $\mathrm{R}$ & $\mathrm{R}$ & $\mathrm{R}$ \\
\hline $25 / 26$ & Híbrido & $?$ & $\mathrm{~S}$ & $\mathrm{~S}$ \\
\hline $31 / 32$ & Híbrido & $\mathrm{R}$ & $\mathrm{S}$ & $\mathrm{S}$ \\
\hline $43 / 44$ & Híbrido & $\mathrm{R}$ & $\mathrm{S}$ & $\mathrm{S}$ \\
\hline $49 / 50$ & Híbrido & $\mathrm{R}$ & $\mathrm{R}$ & $\mathrm{R}$ \\
\hline $55 / 56$ & Híbrido & $\mathrm{S}$ & $\mathrm{S}$ & $\mathrm{S}$ \\
\hline $61 / 62$ & Híbrido & $?$ & $\mathrm{~S}$ & $\mathrm{~S}$ \\
\hline $67 / 68$ & Híbrido & $\mathrm{R}$ & $\mathrm{S}$ & $\mathrm{S}$ \\
\hline $73 / 74$ & Híbrido & $\mathrm{S}$ & $\mathrm{S}$ & $\mathrm{S}$ \\
\hline $109 / 110$ & Híbrido & $\mathrm{R}$ & $\mathrm{R}$ & $\mathrm{R}$ \\
\hline $127 / 128$ & Híbrido & $?$ & $\mathrm{~S}$ & $\mathrm{~S}$ \\
\hline $133 / 134$ & Híbrido & $\mathrm{R}$ & $\mathrm{S}$ & $\mathrm{S}$ \\
\hline $159 / 160$ & Híbrido & $\mathrm{R}$ & $\mathrm{R}$ & $\mathrm{R}$ \\
\hline $165 / 166$ & Híbrido & $?$ & $\mathrm{~S}$ & $\mathrm{~S}$ \\
\hline $219 / 220$ & Híbrido & $?$ & $\mathrm{~S}$ & $\mathrm{~S}$ \\
\hline AGROBEL 910 & Híbrido & $\mathrm{R}$ & $\mathrm{NT}$ & $\mathrm{R}$ \\
\hline AGROBEL 920 & Híbrido & $\mathrm{R}$ & $\mathrm{NT}$ & $\mathrm{R}$ \\
\hline AGROBEL 960 & Híbrido & $\mathrm{R}$ & $\mathrm{NT}$ & $\mathrm{R}$ \\
\hline AGROBEL 965 & Híbrido & $\mathrm{R}$ & N T & $\mathrm{R}$ \\
\hline BRS 191 & Híbrido & $\mathrm{S}$ & $\mathrm{NT}$ & $\mathrm{S}$ \\
\hline C11 & Híbrido & $\mathrm{R}$ & $\mathrm{NT}$ & $\mathrm{R}$ \\
\hline EXP38 & Híbrido & $\mathrm{R}$ & $\mathrm{NT}$ & $\mathrm{R}$ \\
\hline M734 & Híbrido & $\mathrm{R}$ & $\mathrm{NT}$ & $\mathrm{R}$ \\
\hline M742 & Híbrido & $\mathrm{R}$ & $\mathrm{NT}$ & $\mathrm{R}$ \\
\hline RUMBOSOL91 & Híbrido & $\mathrm{R}$ & N T & $\mathrm{R}$ \\
\hline CMS ALCEM & Linhagem & $\mathrm{S}$ & $\mathrm{NT}$ & $\mathrm{S}$ \\
\hline CMS FM & Linhagem & $\mathrm{S}$ & $\mathrm{NT}$ & $\mathrm{S}$ \\
\hline CMS LCEU & Linhagem & $\mathrm{S}$ & $\mathrm{NT}$ & $\mathrm{S}$ \\
\hline CMS VM & Linhagem & $\mathrm{S}$ & NT & $\mathrm{S}$ \\
\hline HA ALCEM & Linhagem & $\mathrm{S}$ & $\mathrm{NT}$ & $\mathrm{S}$ \\
\hline HA FM & Linhagem & $\mathrm{S}$ & $\mathrm{NT}$ & $\mathrm{S}$ \\
\hline HA LCEU & Linhagem & $\mathrm{S}$ & $\mathrm{NT}$ & $\mathrm{S}$ \\
\hline HA REM & Linhagem & $\mathrm{S}$ & $\mathrm{NT}$ & $\mathrm{S}$ \\
\hline HA VU & Linhagem & $\mathrm{S}$ & $\mathrm{NT}$ & $\mathrm{S}$ \\
\hline OASIS - F & Linhagem & $\mathrm{S}$ & $\mathrm{NT}$ & $\mathrm{S}$ \\
\hline OASIS - M & Linhagem & $\mathrm{S}$ & $\mathrm{NT}$ & $\mathrm{S}$ \\
\hline SAUDADE - F & Linhagem & $\mathrm{S}$ & $\mathrm{NT}$ & $\mathrm{S}$ \\
\hline SAUDADE - M & Linhagem & $\mathrm{S}$ & $\mathrm{NT}$ & $\mathrm{S}$ \\
\hline 7701 & Linhagem & $\mathrm{NT}$ & $\mathrm{S}$ & $\mathrm{S}$ \\
\hline 7702 & Linhagem & $\mathrm{NT}$ & $\mathrm{S}$ & $\mathrm{S}$ \\
\hline 7726 & Linhagem & $\mathrm{NT}$ & $\mathrm{S}$ & $\mathrm{S}$ \\
\hline 7800 & Linhagem & $\mathrm{NT}$ & $\mathrm{S}$ & $\mathrm{S}$ \\
\hline 7801 & Linhagem & $\mathrm{NT}$ & $\mathrm{S}$ & $\mathrm{S}$ \\
\hline $20+$ & Linhagem & $\mathrm{NT}$ & $\mathrm{R}$ & $\mathrm{R}$ \\
\hline $44+$ & Linhagem & $\mathrm{NT}$ & $\mathrm{S}$ & $\mathrm{S}$ \\
\hline $50+$ & Linhagem & $\mathrm{NT}$ & $\mathrm{R}$ & $\mathrm{R}$ \\
\hline $56+$ & Linhagem & $\mathrm{NT}$ & $\mathrm{S}$ & $\mathrm{S}$ \\
\hline $68+$ & Linhagem & $\mathrm{NT}$ & $\mathrm{S}$ & $\mathrm{S}$ \\
\hline $134+$ & Linhagem & $\mathrm{NT}$ & $\mathrm{S}$ & $\mathrm{S}$ \\
\hline Embrapa 122 & Testemunha & $\mathrm{S}$ & $\mathrm{S}$ & $\mathrm{S}$ \\
\hline
\end{tabular}

* S - suscetível; R - resistente; NT - não testado; ? - não definido
2001, outras raças foram identificadas naquele país, como as raças 710,730 e 770, afetando os genótipos resistentes às raças que ocorriam no passado (300 e 330) (19).

A avaliação dos genótipos comerciais demonstrou que o híbrido BRS 191 e a variedade Embrapa 122 mostraram esporulação abundante nos cotilédones e foram considerados suscetíveis ao patógeno. Os híbridos AGROBEL 910, AGROBEL 920, AGROBEL 960, AGROBEL 965, C11, EXP38, M734, M742 e RUMBOSOL 91 não apresentaram esporulação e foram considerados resistentes. As testemunhas suscetíveis CMSHA30379NW22 e 89V23960 também apresentaram esporulação (Tabelas 2 e 3 ). Cabe salientar que a variedade Embrapa 122 teve sua origem a partir da variedade francesa Issanka (2), que é suscetível a todas as raças de $P$. halstedii. Os materiais identificados no presente trabalho como resistentes são híbridos desenvolvidos na Argentina, onde as empresas de melhoramento genético de girassol têm por lei a obrigação de desenvolver materiais resistentes aos isolados locais de P. halstedii. Assim, as fontes de resistência utilizadas nesses programas de melhoramento, como, por exemplo, a linhagem RHA 274 (resistente às raças americanas 1, 2, $6 \mathrm{e}$ 7), têm sido suficientes para controlar o patógeno (1).

Entre os 17 híbridos experimentais do programa de melhoramento genético de girassol da Embrapa Soja testados, quatro apresentaram resistência à raça 330 do agente causal do míldio (19/20, 49/50, 109/ 110 e 159/160) e os demais foram suscetíveis. Entre as linhagens avaliadas, apenas os parentais $20+$ e $50+$ não apresentaram esporulação nos cotilédones e foram considerados resistentes (Tabela 3 ).

A avaliação dos genótipos de girassol ornamental, inoculados com suspensão de zoosporângios da raça 330 do agente causal do míldio, demonstrou que todos exibiram esporulação abundante nos cotilédones, sendo categorizados como suscetíveis, exceto o híbrido Agrobel 960, incluído como testemunha resistente (Tabela 4). O mesmo resultado foi observado nos dois testes realizados. Observando a sintomatologia, plantas com infecção sistêmica de míldio apresentam crescimento lento ou nanismo, com folhas cloróticas e anormalmente grossas, hastes quebradiças com capítulos eretos e, geralmente, estéreis (6). Certamente, plantas ornamentais com esses sintomas não são aptas para comercialização. A produção de flores é feita normalmente em áreas de cultivo intenso, onde as doenças podem ser limitantes ou até mesmo inviabilizar o uso da área. Plasmopara halstedii produz oósporos de parede fina, que são estruturas de resistência, produzidas sexualmente, essenciais para sua perpetuação (6). Depois de introduzido numa área, a erradicação do patógeno é difícil devido à formação de oósporos, que podem permanecer viáveis no solo por muitos anos (20).

Por se tratar de praga quarentenária A1 (exceto a raça 2 americana, atualmente raça 300), em novembro de 2002, a Embrapa Soja notificou o Ministério da Agricultura, Pecuária e Abastecimento (MAPA) sobre a ocorrência da raça 330, em experimentos de campo, em Londrina, PR. Foi implementado um Plano de Erradicação, conforme o preconizado na Norma Internacional de Medidas Fitossanitárias NIMF $n^{\circ} 9$ (15). Devido às medidas de erradicação tomadas, o MAPA considerou que o patógeno fosse mantido na categoria de praga quarentenária A1.

O tratamento de sementes com fungicidas específicos para $P$. halstedii, como o metalaxyl, é obrigatório em alguns países, como a França e a Argentina, em variedades de polinização livre ou cultivares híbridas suscetíveis. O metalaxyl, graças à sua propriedade sistêmica, permite controlar contaminações primárias e assegura uma boa proteção nos primeiros estádios de desenvolvimento da cultura $(3,16)$. Entretanto, no Brasil, o mesmo não está registrado 
Tabela 4. Reação de genótipos de girassol ornamental inoculados com Plasmopara halstedii raça 330, em Londrina, PR, em abril e outubro de 2003

\begin{tabular}{|c|c|c|}
\hline Genótipo & Identificação* & Reação \\
\hline $89 V 23960$ & Testemunha & Suscetível \\
\hline Agrobel 960 & Testemunha & Resistente \\
\hline BRS Capri M & Variedade & Suscetível \\
\hline BRS Encanto M & Variedade & Suscetível \\
\hline BRS Oásis & Híbrido & Suscetível \\
\hline BRS Paixão M & Variedade & Suscetível \\
\hline BRS Pesqueiro M & Variedade & Suscetível \\
\hline BRS Refúgio M & Variedade & Suscetível \\
\hline BRS Saudade M & Variedade & Suscetível \\
\hline BRS Saudade U & Variedade & Suscetível \\
\hline CMS 10090 & Parental $\subseteq$ BRS Capri M & Suscetível \\
\hline CMS 10026 & Parentalc BRS Encanto M & Suscetível \\
\hline CMSHA30379NW22 & Parentalç BRS Oásis & Suscetível \\
\hline CMS 10162 & Parentalç BRS Paixão M & Suscetível \\
\hline CMS 10004 & Parentalc BRS Pesqueiro M & Suscetível \\
\hline CMS 10115 & Parentalc BRS Refúgio M & Suscetível \\
\hline CMS 10034 & Parentalç BRS Saudade M & Suscetível \\
\hline CMS 10048 & Parentalç BRS Saudade U & Suscetível \\
\hline HA 10091 & Parental 3 BRS Capri M & Suscetível \\
\hline HA 10027 & Parental $\delta$ BRS Encanto M & Suscetível \\
\hline HA30379NW22 & Parental BRS Oásis & Suscetível \\
\hline HA 10163 & Parental 3 BRS Paixão M & Suscetível \\
\hline HA 10002 & Parental $\measuredangle$ BRS Pesqueiro M & Suscetível \\
\hline HA 10138 & Parental $\measuredangle$ BRS Refúgio M & Suscetível \\
\hline HA 10035 & Parental BRS Saudade M & Suscetível \\
\hline HA 10049 & Parental $\measuredangle$ BRS Saudade U & Suscetível \\
\hline
\end{tabular}

* M - multicapitulado; U - unicapitulado

para tratamento de sementes de girassol, o que inviabiliza sua recomendação pela pesquisa.

Desse modo, uma estratégia para o controle do míldio é o desenvolvimento de genótipos resistentes. O uso de cultivares resistentes é o método mais seguro de prevenção da doença e é feito nos países com tradição no cultivo do girassol, como a França e a Argentina $(3,16)$. A resistência ao míldio é oligogênica e dominante, controlada por genes codificados por $P l$ (6). Assim, o programa de melhoramento genético de girassol da Embrapa Soja está desenvolvendo esforços no sentido de incorporar resistência à raça 330 de $P$. halstedii nas cultivares de girassol para extração de óleo e ornamental.

Os resultados permitem concluir que a raça de $P$. halstedii que ocorreu no campo experimental da Embrapa Soja em 1998, 2001 e 2002 é a raça 330 (antiga raça 7 americana); as cultivares Embrapa 122 e BRS 191 são suscetíveis à raça 330 de $P$. halstedii; as cultivares AGROBEL 910, AGROBEL 920, AGROBEL 960, AGROBEL 965, C11, EXP38, M734, M742 e RUMBOSOL 91 são resistentes à raça 330 do patógeno e podem ser indicados aos agricultores para uso em regiões de risco de ocorrência da doença; entre os materiais do programa de melhoramento genético de girassol da Embrapa Soja, os híbridos 19/20, 49/50, $109 / 110$ e $159 / 160$ e os parentais $20+$ e $50+$ apresentam resistência à raça 330 do agente causal do míldio e podem continuar sendo utilizados nos trabalhos que objetivam a resistência genética à doença; e as cultivares de girassol ornamental BRS Capri M, BRS Encanto M, BRS Oásis, BRS Paixão M, BRS Pesqueiro M, BRS Refúgio M, BRS Saudade M e BRS Saudade U não são indicadas para uso em áreas com histórico de ocorrência da raça 330 de $P$. halstedii.

\section{AGRADECIMENTOS}

Aos técnicos agrícolas Allan Misael Flausino, Reinaldo Campos e Roberval Aparecido Fagundes, pelo auxílio na instalação e na avaliação dos experimentos. A divulgação destes resultados de pesquisa foi autorizada pelo Ministério da Agricultura, Pecuária e Abastecimento (MAPA), pelo parecer técnico ${ }^{\circ}$ RASC/5053/MAPA, de 01/04/2004. Este artigo foi aprovado para publicação pelo Comitê de Publicações da Embrapa Soja sob o número 003/2006.

\section{REFERÊNCIAS BIBLIOGRÁFICAS}

1. Castaño, F.; Pereyra, V.; Escande, A. Downy mildew of sunflower in Argentina. In: Symposium III Sunflower Downy Mildew, 1998, Fargo. Proceedings. Paris: International Sunflower Association, 1998. p.139.

2. Castiglioni, V.B.R.; Leite, R.M.V.B.C.; Oliveira, M.F. Girassol Embrapa 122 - V2000. Londrina: EMBRAPA, CNPSo, 1997. 6p. 1 folder.

3. Davet, P.; Pérès, A.; Regnault, Y.; Tourvieille, D.; Penaud, A. Les maladies du tournesol. Paris: CETIOM, 1991. 72p.

4. Ferreira, L.P.; Henning, A.A.; Yorinori, J.T.; França Neto, J.B.; Schuck,E.; Lemos, E.C.; Azeredo, J.A.P. Ocorrência do míldio (Plasmopara halstedii) em girassol, no Brasil. In: Congresso Brasileiro de Sementes, 3., 1983, Campinas. Resumos. Campinas: ABRATES, 1983. p.93.

5. Gulya, T.J. Everything you should know about downy mildew testing but were afraid to ask. In: Sunflower Research Workshop, 18., 1996, Fargo. Proceedings. Bismarck: National Sunflower Association, 1996. p.39-48.

6. Gulya, T.J.; Rashid, K.Y.; Masirevic, S.M. Sunflower diseases. In: Schneiter, A.A. (Ed.) Sunflower technology and production. Madison: American Society of Agronomy, 1997. p.263-379.

7. Gulya, T.J.; Tourvieille de Labrouhe, D.; Masirevic, S.M.; Penaud A.; Rashid, K.Y.; Viranyi, F. Proposal for standardized nomenclature and identifications of races of Plasmopara halstedii (sunflower downy mildew). In: Symposium III Sunflower Downy Mildew, 1998, Fargo. Proceedings. Paris: International Sunflower Association, 1998. p.130-136.

8. Henning, A.A.; França Neto, J.B. Physiological race and sources of resistance to downy mildew (Plasmopara halstedii (Farl.) Berl. $\&$ de Toni) in Brazil. In: International Sunflower Conference, 11., 1985, Mar del Plata. Proceedings. Toowoonba: International Sunflower Association, 1985. v.2, p.407-409.

9. Leite, R.M.V.B.C. Doenças do girassol (Helianthus annuus). In: Kimati, H.; Amorim, L.; Rezende, J.A.M.; Bergamin Filho, A.; Camargo, L.E.A. (Ed.). Manual de fitopatologia: doenças das plantas cultivadas. 4. ed. São Paulo: Agronômica Ceres, 2005a. v.2, p.385-399.

10. Leite, R.M.V.B.C. Reação de genótipos de girassol ornamental ao míldio (Plasmopara halstedii). In: Reunião Nacional de Pesquisa de Girassol, 16., 2005, Londrina. Anais. Londrina: Embrapa Soja, 2005b. p. 111-113.

11. Leite, R.M.V.B.C.; Oliveira, M.F. Detecção e variabilidade de Plasmopara halstedii, agente causal do míldio do girassol, em Londrina, PR. In: Reunião Nacional de Pesquisa de Girassol, 13., 1999, Itumbiara. Resumos. Londrina: Embrapa Soja, 1999. p.143-144.

12. Leite, R.M.V.B.C.; Oliveira, M.F. History of downy mildew of sunflower in Brazil. In: Symposium III Sunflower Downy Mildew, 1998, Fargo. Proceedings. Paris: International Sunflower Association, 1998. p. 36-37.

13. Leite, R.M.V.B.C.; Rodrigues, S.R.; Oliveira, M.F. Detecção e variabilidade de Plasmopara halstedii no Brasil e avaliação da resistência de genótipos de girassol ao míldio. In: Reunião Nacional de Pesquisa de Girassol, 15., 2003, Ribeirão Preto. Resumos. Campinas: IAC, 2003. 1 CD-ROM.

14. Oliveira, M. F.; Castiglioni, V. B. R. Girassol colorido para o 
Brasil. Londrina: Embrapa Soja, 2003. 1 folder.

15. Organização das Nações Unidas para a Agricultura e a Alimentação. Secretaria da Convenção Internacional de Proteção Fitossanitária. Normas internacionais para medidas fitossanitárias; diretrizes para os programas de erradicação de pragas. Roma, 1998. 11p. (ICPM-98/INFORME).

16. Pereyra, V.; Escande, A. R. Enfermedades del girasol en la Argentina: manual de reconocimiento. Balcarce: INTA, 1994. 113p.

17. Rashid, K.Y. Pathogenic variability in Plasmopara halstedii in Western Canada. In: Symposium III Sunflower Downy Mildew,
1998, Fargo. Proceedings. Paris: International Sunflower Association, 1998. p.30-33.

18. Tourvieille de Labrouhe, D.; Pilorgé, E.; Nicolas, P.; Vear, F. Le mildiou du tournesol. Paris: CETIOM, INRA, 2000. 176p.

19. Vázquez, A. Mejoramiento genético. In: Diaz-Zorita, M.; Duarte, G. Manual práctico para el cultivo de girasol. Buenos Aires: Hemisferio Sur, 2002. p.61-76.

20. Zimmer, D.E.; Hoes, J.A. Diseases. In: Carter, J.F. (Ed.) Sunflower science and technology. Madison: American Society of Agronomy, 1978. p.225-262. 